shed were transferred from the South Ground to the position formerly occupied by the old instrument, to make way for the new buildings in the South Ground.

The mean temperature of the year 1890 was $48^{\circ} \cdot 6$, being $0^{\circ} .6$ below the average of the preceding 4\% years. The highest air temperature in the shade was $82^{\circ} \cdot 8$ on August 5 , and the lowest $13^{\circ} \mathrm{I}$ on March 4. This latter is the lowest temperature registered in March since $\mathrm{I} 84 \mathrm{r}$, being the same us that recorded on March I3, Inิ45. The mean monthly temperature in 1890 was below the average in all months excepting January, March, May, and September. In December it was below the average by $10^{\circ} \mathrm{o}$, and in January above by $5^{\mathrm{c}} \cdot 2$.

The mean daily motion of the air in I 890 was 272 miles, being ro miles below the average of the preceding 23 years. The greatest daily motion was 837 miles on January 26 , and the least 32 miles on August 6. The greatest pressure registered was 14.5 pounds on the square foot on January 26.

During the year I890 Osler's anemometer showed an excess of about three revolutions of the vane in the positive direction N., E., S., W., N., excluding the turnings which are evidently accidental.

The number of hours of bright sunshine recorded during 1890 by the Campbell-Stokes sunshine instrument was 1255, which is about 35 hours below the average of the preceding I3 years, after making allowance for difference of the indications with the Campbell and Campbell-Stokes instruments respectively. The aggregate number of hours during which the sun was above the horizon was 4454 , so that the mean proportion of sunshine for the year was $0^{\circ} 282$, constant sunshine being represented by $I$.

The rainfall in 1890 was $21 \%$ inches, being $2 \%$ inches below the average of the preceding 49 years.

The winter of I890-9I was remarkable for a long period of exceptionally cold weather which commenced on November 25, 1890. From this day till January 22 the mean temperature on every day except January I3 was below the average. The temperature was continuously below $32^{\circ}$ on November 27,28 , December Io to $19,22,23,25,28$ to 30 , January 2,6 to 8, IO, II, I7 to 19. The greatest defects from the average of 20 years were on November $28\left(-19^{\circ} \mathrm{I}\right)$, December $22\left(--20^{\circ} \cdot 7\right)$, and January Io $\left(-19^{\circ} 3\right)$. The lowest temperatures recorded during the three months were $18^{\circ} \cdot 3$ on November $28,13^{\circ} 4$ on December 22 , and $12^{\circ} \cdot 0$ on January ro. The mean temperature of December 1890 was $29^{\circ} .8$, or $10^{\circ} \circ$ below the average of the preceding 49 years, the coldest December on record since $184 \mathrm{I}$ previous to $180 \mathrm{o}$ being that of 1879 , whose mean temperature was $32 \% 4$. In this same month, December 1890 , only $2^{\text {h }} \cdot 4$ of sunshine were recorded.

Chronometers, Time Signals, and Longitude Operations.--The number of chronometers and deck watches now being tested at the Observatory is 169 ( $1 \mathrm{I} 3$ box chronometers, 20 pocket chronometers, and 36 deck watches). The annual competitive trial of chronometers commences on July 4, and the trial of deck watches on October 24.

The time-balls at Greenwich, Deal, and Devonport are next referred to.

The reductions for the longitude Paris-Greenwich are now completed and ready for publication. In reference to the discrepancy between the results of the French and English observers, mentioned in the last Report, Commandant Defforges visited Greenwich in June I\&go, and went carefully through the reductions with $\mathrm{Mr}$. Turner and Mr. Lewis. No mistake was found in the work, but several questions of some importance were raised. The results of the discussion and of subsequent correspondence are summed up in two papers by $\mathrm{Mr}$. Turner and one by Colonel Bassot and Commandant Defforges. in the Monthly Notices of the Royal Astronomical Society, vol. li. pp. 155,407 , and 413 respectively. As the matter now stands, the English definitive result for the difference of longitude between the Greenwich transit-circle and Cassini's meridian is $9^{\mathrm{m}} 20^{\mathrm{s}} \cdot 86$, while the French result (not yet published) is about $\mathrm{O}^{5} \mathrm{I} 5$ greater, a discordance which, though only about half of that found in the preliminary discussion, is still so large, that there seems to be no alternative but to repeat the work with special precautions suggested by the experience gained.

The proposal to determine the longitude of Montreal as the base station for the Geodetic Survey having been sanctioned by the Admiralty last December, arrangements have been made in concert with Prof. McLeod, of the McGill College Observatory, Montreal, for a determination of the longitudes Montreal-Canso-WatervilleGreenwich, the termini of the cable, Canso and Waterville, being occupied as longitude and not merely as transmitting stations, a course which seems advisable in view of the great geodetic importance of these points. The necessary funds have been voted, and the Commercial Cable Company have generously granted the use of their cable.

The determination of the longitude of Washington has been deferred for the present.

During the past year, Lieutenants Heming, Monro, and Smyth, R.N., and Captain Haynes, R.E., have at various times been instructed in transit-observing. Mr. S. Hirayama, of the Tokio Observatory, was at work for some weeks studying the general organization of the Observatory.

\section{THE CLASSIFICATION OF THE TUNICATA} IN RELATION TO EVOLUTION.

THE detailed classification of the Tunicata, and especially of the so-called "Compound Ascidians," has usually been found a matter of special difficulty by systematists, and each successive investigator has discovered grounds for modifying in important respects the grouping of genera and families established by his predecessors. A glance at the systems of Giard, Della Valle, von Drasche, and Lahille, all of recent date (i.e. post-Darwinian, and since the introduction of modern methods and the recognition of the Tunicata as Chordata), shows the notable want of agreement between competent authorities. There is probably a special reason for this exceptional diversity of opinion, and I believe the cause is to be found in the course of evolution or phylogeny of the group, and especially in the complex relations between the Compound forms and the other Tunicata.

In fact, if the matter be regarded from the point of view of the consistent evolutionist, the special difficulties vanish, the complicated relationships between groups (which can only be represented by dendritic diagrams, or even in some cases by networks) become explicable and natural, the great diversity in value of the assemblages of forms known as "genera" and "species" is simply what would be expected, and the differences between the various classificatory systems (allowing for a few errors which have been corrected by later investigations) can be accounted for, and the conflicting opinions of the authors reconciled. But, on the other hand, if the subject be approached from the standpoint of the pure systematist, whose object is to divide and subdivide into clearly defined groups of approximately equal value, and to recognize only "good" genera and species, nothing but confusion results; it becomes practically impossible to distinguish and arrange naturally the groups of Simple and Compound Ascidians; and some of the most interesting and instructive points, such as the gradation of varieties into species and species into genera, and the individual variations in specific characters, are altogether lost sight of.

These views were expressed partly in my Reports

No. I I 28 , vor. 44$]$ 
on the Challenger Tunicata, but further work sinceon some very extensive collections from Australian seas and on the Ascidians of our own coasts-has convinced me that the only rational explanation of the protean forms and labyrinthine inter-relations of the Ascidians is to be found in regarding the group as one in process of evolution, where many of the species, genera, \&c., have not yet become markedly differentiated by the elimination of intermediate forms, and where the animals are so much at the mercy of their environment that a special premium is set upon useful characters (if, indeed, there are any "specific" characters which are not useful), and where, consequently, the relations between modification of structure and conditions of existence brought about by the action of natural selection are exceptionally evident. Adopting, then, this view, the following difficult subjects of dispute, and probably others with which I am not concerned at present, can be, I think, satisfactorily explained: (I) the connection of the Simple with the Compound Ascidians, and the classification of the latter; (2) the value of some modifications of the branchial sac (3) the position of the Polystyelidx; (4) the relations between the sub-families and genera of the Cynthiidæ and (5) the numerous "species" of the genus Botryllus.

(I) If the attempt is made (as in most classifications) to regard the Compound Ascidians as a group distinct from the Ascidiæ Simplices, and forming either a parallel or a divergent line in regard to the latter, one meets at once with the serious difficulty that the Compound Ascidians show affinities with the Simple at several distinct points. Three investigators approaching the Compound Ascidians after the previous study of certain Simple Ascidians-say, the first fresh from Ciona, Ecteinascidia, and Clavelina, the second from Perophora, and the third from Styela and Polycarpa-could each make out a good case for the view that his new subjects were most closely connected with the genera he had just been working at. The first could demonstrate the undoubted relations, in external form and in structure of branchial sac, between Clavelina and Chondrostachys, Colella and the other Distomida; the second might point to the similarity (on which I personally lay no stress) of Perophora and the Botryllidæ, in the relations of alimentary canal to branchial sac; and the third could show the close similarity between the Styelinæ and the Compound forms Synstyela, Goodsiria, and Chorizocormus in nearly every detail of internal structure : and all three would be partly right, and therefore unlikely to agree upon any one system of classification.

But when the attempt is made seriously to form a conception of the past history or evolution of the forms in question, it becomes obvious that the Compound Ascidians are not a natural, but an artificial group. That is, they are not the whole surviving descendants of a single group of ancestors, but are polyphyletic in origin, being derived from several distinct lines of ancestry which have arisen independently from different kinds of Simple Ascidians, and have since acquired the common characteristic of being able to reproduce by gemmation so as to form compact colonies in which the members (ascidiozooids) are embedded in a common test or investing mass. We know with as much certainty as we know anything in such phylogenetic inquiries that the ancestral Tunicates were not colonies, and that reproduction by gemmation was not a primitive character. This property has, then, been acquired secondarily by some ancestral Simple Ascidians, and may very possibly have been acquired more than once (though this is not at all necessary for my theory of the polyphyletic origin). It follows from this view (which I have expressed before, but now feel more certain of from recent work), that if we are to retain the group Ascidiæ Compositæ, or Synascidiæ, in our system, we must represent it as linked on to the Ascidiæ Simplices, at three points at least, and we must not attempt to arrange the families and genera in a series diverging from any one of these points alone ; or if we do, we need not be surprised when we arrive at obviously unnatural arrangements which are in conflict with the classifications of our fellow-workers.

On the other hand, we might abolish the group Ascidia Compositæ altogether as a sub-order of Ascidiaceæ, on the ground that it is not a natural group (i.e. a compact set of descendants from a common ancestor-a single branch of the genealogical tree).

But if we adopt this course with the Compound Ascidians, the same argument might be used in connection with other polyphyletic groups throughout the animal kingdom. They should all be broken up, it might be urged, as being artificial assemblages. And that would be a perfectly logical and definite position to take up, and one for which a good deal could be said, but before adopting it zoologists should remember that it involves a loss as well as a gain. If it gives "the system" a certain precision, and an advance of a step or two towards the goal of a completely natural classification, it at the same time destroys the recognition of characteristics which certain forms possess in common. In whatever manner they have been obtained, there is no doubt that Compound Ascidians of the present day possess certain features by which they can be identified as Compound Ascidians, and this fact is surely worthy of recognition in our "system." My own opinion, then, is that the group Ascidiz Compositæ should still be retained, but that its polyphyletic origin and multiple connection with the Ascidiæ Simplices should be carefully borne in mind when drawing up any scheme of classification, or discussing affinities.

(2) Some of the ideas noted above, and others to be discussed below, took definite form lately in reading a recently published memoir by M. Fernand Labille, ${ }^{1}$ in which, while giving a number of important original observations on the anatomy and bionomics of the Ascidians (and especially of the Compound forms) of the French coasts, the author introduces what I cannot help thinking in some respects an unfortunate attempt to remodel the classification of the Tunicata on lines which he communicated a few years ago to the French Association (Congrès de Toulouse, 1887), and now elaborates in detail. He regards the branchial sac as the most important organ in the Tunicata, and so it is in some respects; but that is not sufficient reason for regarding its modifications in structure as the sole characteristics of the primary groups. For example, the Appendicularians, instead of being called Larvacea or Copelata, and characterized by the presence of a tail containing the urochord, are placed in a group "Atremata," defined by the absence of stigmata in the branchial sac. The openings in question (stigmata) are not even such important structures as the primary branchial clefts (gill-slits), but are merely the secondary slits placin: the cavity of the branchial sac in communication with the peribranchial or atrial cavity, and are of nothing like such high morphological value as the presence or absence of a urochord, and of the two primitive atriopores, and the other well-known characteristics employed in former classifications as distinguishing the Appendiculariida:. Some of the Thaliacea are placed by Lahille in a group (Hemitremata) of primary importance, by themselves, because they have the stigmata rudimentary or imperfectly formed, while the other Thaliacea are united with all the remaining Tunicata, because they are supposed to be alike in having complete stigmata.

Then, again, an altogether fictitious value is given by Lahille to the presence of internal longitudinal bars in the branchial sac, especially since he shows (as had been done by former writers) that these bars develop as outgrowths "Recherches sur les Tuniciers des Côtes de France" (Toulouse, 1800 ).
Which, however, is not really the case. The apertures in the walls of he branchial sac in Lahille's "Eutremata" are not always homologous structures. In the genus Culeolus, for example, there are no true stigmata.

NO, I I 28 , VOL. 447 
from the connecting ducts, and that intermediate conditions can be found in which the bars can neither be said to be absent nor present. He describes this condition in his new species Perophora banyulensis, and it is also present in $P$. viridis, Verrill, and in various other Simple Ascidians, as has been shown in the Challenger Reports and elsewhere.

Such cases, although rather perplexing to the systematist, are perfectly natural from an evolutionist's point of view, and they certainly make one regard with some suspicion large groups founded upon any such one character. Consequently, Lahille's order "Stolidobranchiata," characterized solely by the presence of a particular kind of internal longitudinal bar in the branchial sac, is, in my opinion, a most unnatural assemblage of the families Polystyelidæ, Cynthiidæ, Molgulidæ, and Botryllidæ, which cannot be retained. It is not safe to trust to the modifications of structure of one organ in the detailed classification of a group, and it is especially unsafe where that organ is, as in the case of the branchial sac, of great physiological importance, and so is liable to be considerably modified in accordance with the mode of life in forms which are otherwise closely related. Morphological characters of less functional importance are more likely to be retained unaltered, and so indicate real genetic affinity.

Surely Lahille does not seriously mean to contend that the internal longitudinal bars in the branchial sac of the Botryllidæ, Cynthiidæ, \&c., are different in any morphological sense from the similar bars found in other Ascidians, such as the Ascidiidæ. Although they may be slightly different ${ }^{1}$ in their relations to the wall of the sac in these two groups, being attached throughout their length in Botryllus in place of only at the angles of the meshes as in Ascidia, and are therefore somewhat different in their development (ontogeny), there can scarcely be any doubt that in their origin (phylogeny) all such bars in the branchial sac are alike, and are therefore homologous structures.

(3) It follows from what has been said above in regard to the origin of the Compound Ascidians, that even though the group Polystyelidæ is placed (as was the case in the Challenger Report) in the Ascidiæ Compositæ, it is not thereby widely separated from its relations amongst the Simple Ascidians. If the sub-order Ascidiæ Compositæ is retained, then the Polystyelidæ must go in it, since they form definite permanent colonies with the ascidiozooids embedded in a common test; but of course these forms are very similar in many respects to Styela and Polycarpa-that being one of the points of contact between Compound and Simple Ascidians-and therefore I can agree fully with all that Lacaze-Duthiers and Delage say in favour of that relationship. The matter stands simply thus:- If Ascidiæ Compositæ is retained, the Polystyelidæ must be placed in it at the nearest point to Polycarpa amongst Ascidiæ Simplices; while if Ascidiæ Compositæ is abolished, the Polystyelidæ will form a family or a sub-family (it matters little which) alongside the Styelinæ under Ascidiæ Simplices. To go further, and break up even the genera of the Polystyelidæ, placing the species beside those Cynthiidæ they resemble most in the structure of the branchial sac, would be to give no value at all to the property of reproduction by gemmation and the formation of colonies.

(4) It has long been recognized that there are two groups of forms in the family Cynthiidæ, those which centre around Styela and those related to Cynthia, and when the remarkable stalked forms, such as Boltinia and the deep-sea genus Culeolus, had been added, I defined these three groups as sub-families under the names Styelinæ, Cynthinæ, and Bolteninæ. Leaving the last

I Even this difference is not constant. In some Botryllidæ, aud I think in all Polystyelida and many Cynthiida, the relations of the bars in the adult are precisely as in Ascidia, Ciona, and Ecteinascidia.

NO. I I 28 , VOL. 44] out of the question, we have the two former distinguished amongst other characters by the fact that the Styelinæ have never more than eight folds in the branchial sac, and have simple tentacles, while the Cynthinæ have always more than eight folds, and compound tentacles.

A few years ago these seemed well-established characters to which there were no exceptions. Last year, however, Lacaze-Duthiers and Delage published a preliminary account of a Cynthia from the French coasts, with only eight folds (as in Styelinæ) in its branchial sac ; while Traustedt has discovered that the Cynthia tesselata of Forbes has four folds on the right side of the branchial sac and three on the left (like some Styelinæ), although the tentacles are compound (as in Cynthinæ); and I find that long ago Alder described the reverse case in Cynthia tuberosa, Macg., where there are twelve folds in the branchial sac (Cynthinæ), although the tentacles are simple (Styelinæ). Thus the two links required to unite the characters ${ }^{1}$ of Styelinæ and Cynthinæ have been found, which is perfectly natural and satisfactory to the evolutionist, and the question for the systematist now is, Must these two subfamilies be united? I think not. I believe that they are natural groups, and that they are really as widely separated from one another in their typical members as we ever supposed them to be, although not so completely isolated from one another by the extinction of intermediate forms.

If these interesting links, to which attention has just been drawn, and which are apparently not common nor widely distributed forms, had become extinct a few years ago, the Styelinæ and Cynthinæ would without question be justly regarded as widely separated groups. And the present position is merely that a few forms are known which if not bridging over at least lie as stepping-stones in the gap; while the vast majority of the species in question are clearly distinguishable by easily recognized characters into two definite sets. 'This last fact has an importance which entitles it to recognition. I am far from wishing to ignore the imfortance of such intermediate forms ; in fact I am more likely, I fancy, to regard them with undue interest; but after all they are single species, minute twigs of the great branch under consideration, while long series of typical Styelinæ and Cynthinæ-the many species of Styela and of Polycarpa, of Cynthia and of Microcosmus - can be divided into two groups by their tentacles and their branchial folds, and I believe we are justified in giving expression to this natural grouping by retaining the two sub-families in our system of classification. It need not lead to any difficulties: the intermediate forms can be placed as an appendage to the sub-family taken first. We cannot now pretend to draw hard and fast lines round all our groups, a serial or a tabular classification will always give erroneous impressions, and in a phylogenetic arrangement the linking forms will appear in their proper places as little twigs between the two great branches.

(5) The genus Botryllus seems to contain an endless series of forms which might be (and many of which have been) described as separate species. Giard, twenty years ago, pointed out the great variability of the species in this genus, and described many varieties and local conditions, but the supply is not yet exhausted, and one is almost tempted to conclude that no satisfactory position can be taken up anywhere between the two extremes of either (I) regarding the whole genus (or even the family Botryllidæ) as an enormous protean species, or (2) describing nearly every colcny as a separate species.

From the point of view of the systematist or speciographer who wants "good" and well-defined species, this group of Ascidians must be an abomination, but to the student of evolution it is full of interest. Here, if anywhere, characters can be seen varying in all

I These are the chief characters, $l$ ut there are others, such as the condition of the stomach and digestive glands. 
directions and to almost all degrees, some variations becoming fixed while others remain indefinite. I am at present examining (with the help of my former student, Miss A. E. Warham, B.Sc.) the anatomical characters of a number of colonies of various Botrylli with the view of finding which characters, if any, can be relied on in distinguishing species or "forms," and I have just seen a series of ascidiozooids of Botryllus smaragdus in which the branchial tentacles, usually regarded as important features in the diagnosis of species, present all variations between eight and sixteen. Every one of the numbers $8,9,10,11,12,13,14,15$, and 16 , is represented by one or more ascidiozooids, although 8 and 16 are those most commonly found. Also several definite arrangements, such as 2 large pigmented tentacles and 6 small, 3 large pigmented and I 3 small, are present, and are connected by all possible gradations. Then, again, we find that the smaller set of these tentacles may be all alike, or may be of two sizes placed longer and shorter alternately, or they may be 2 shorter and 4 longer, or 2 shorter and 5 longer, or 3 shorter and 5 longer, or 4 shorter and 5 longer, or 6 shorter and 5 longer, and so on through the variations. Two or three of the extreme forms, if examined by themselves, might easily be regarded as distinct species.

I have heard it said, and I fancy it may be often thought, that since evolution has changed our conception of a species, the modern biologist need not concern himself with the description and nomenclature and delimitation of those assemblages of variable forms which are known as varieties and species. But to take such a course would be a great mistake. The theory of evolution has given taxonomy and speciography an additional and a very real interest. Now that we know just how much and how little the term species indicates, it has become of great importance that species and varieties should be re-studied from the evolutionary standpoint, that the relations of allied forms should be carefully investigated, the limits of their variation determined, and the effect of their environment ascertained. The Botryllidæ form a specially interesting group for such an investigation.

Many of these more general remarks will no doubt apply to other groups of organisms with as much force as to the Tunicata, but some of the instances discussed above may seem points of mere detail of no great general interest. I believe, however, that they are typical cases illustrating difficulties which may confront any specialist in the course of his endeavour to attain to that important object of biological investigation-a natural or genetic classification of animals and plants.

February.

\section{W. A. HERDMAN.}

\section{PHOTO-STELLAR SPECTRA.}

PR ROF. PICKERING, while retaining the four types of stellar spectra, finds that so many stars show an intermediate stage of development, that, in the Draper Catalogue, letters are substituted for the types. Thus, let ters $A$ to $D$ denote stars of the first type ; $E$ to $L$, stars of the second type; M, stars of Type III.; while $\mathrm{N}$ is reserved for fourth type stars. It seemed of some interest to compare the photographic results with those obtained directly with the spectroscope. For the first and second types, the observations of Vogel " Spect. Beob." - - $\mathrm{I}^{\circ}$ to $+20^{\circ}$ ) were used. The stars in the first four hours of R.A. which occur in both works were examined and tabulated, those being rejected where there was any uncertainty as to type in Vogel's observations. The following table shows the results thus obtained:-

1 "Note on the Classification of Star Spectra in vol. xxvii. Harvard Annals, and on some Stars with Bright Lines."

NO. I I 28 , VOL. 44]

VOGE.L.

Eye observation. Class.

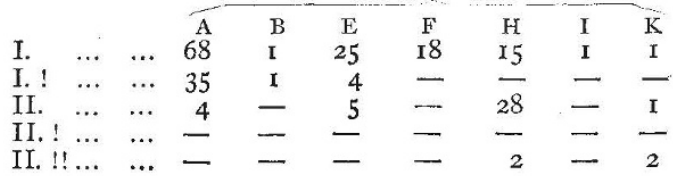

To show the differences in type, the following table has been drawn up :-

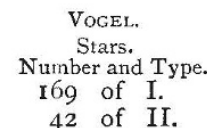

42 of II.

These tables show that, in the case of Type I., nearly half the stars observed with the eye are really Type II. according to the photographs; in the case of Type I.!, four out of the forty, although having a clearly pronounced first type spectrum to the eye, are really second type stars according to the photographs. In the case of the second type, four stars out of forty-two are really first type.

For the third type stars, Dunér ("Sur les Étoiles," \&c.) was consulted, and the following results were obtained:--

DUNÉr.

Eye observation.

Type.

$\begin{array}{llllllllll} & & & \text { A } & \text { E } & \text { F } & \text { H } & \text { I } & \text { K } & \text { M } \\ \text { III. } & \ldots & \ldots & - & - & - & \text { I } 9 & 2 & - & 8 \\ \text { III. } ! & \ldots & \ldots & - & - & - & 24 & 2 & \text { I } & 22 \\ \text { III. } ! ! & \ldots & \ldots & 3 & - & - & \text { I } & \text { I } & \text { I } & 24 \\ \text { III. } 1 ! ! & \ldots & \ldots & \text { - } & \text { I } & \text { I } & 5 & - & - & \text { I } 2\end{array}$

This table may be condensed as follows :JUUNÉr.

Type.

Pickering.

\begin{tabular}{|c|c|c|c|c|c|c|c|}
\hline & I. & & II. & & III. & & Tota \\
\hline III. to III. ! $\ldots$ & - & $\cdots$ & 48 & $\cdots$ & 30 & $\ldots$ & 78 \\
\hline III. "! to III. !!! ... & 3 & $\cdots$ & 23 & $\cdots$ & 12 & $\cdots$ & $3^{8}$ \\
\hline Total & 3 & & 71 & & 42 & & I I 6 \\
\hline
\end{tabular}

The photographs therefore show that only 36 per cent. are third type at all. In order to account for this very remarkable result, the words of Prof. Pickering may be quoted:- "The difference between this (the third) type and the second is much less marked in the photographic than in the visible portion of the spectrum. The most noticeable difference is that, in spectra of the third type, the intensity suddenly changes at the wave-length $476^{\circ} 2$. Rays of greater wave-length than this are fainter than those that are shorter."

It will be seen that three stars of the third type appear as first type stars on the photograph. These are :-

(r) LL. $37 \mathrm{I} 7$, Ih. $55 \mathrm{~m}$. - $9^{\circ} \mathrm{o}^{\prime} 4$, Dunér III. !!: "Les bandes $2-9$ sont fortement développées, très larges et sombres."

(2) D.M. $+\mathrm{I} 7^{\circ} \cdot 1479,6 \mathrm{~h} .56 \mathrm{~m}$. + I $7^{\circ} 53^{\prime} \cdot 8$, Dunér III.!! : "Les bandes $2-8$, et peut-etre 9 , sont visibles; elles sont très larges et fort obscures autant dans le vert-bleu que dans le rouge."

(3) $\tau^{t}$ Serpentis, I $5 \mathrm{~h} .3 \mathrm{Im} .+15^{\circ} 25^{\prime} 9$, Dunér III. !! : "Les bandes sont larges et fortes, surtout dans le vert et dans le bleu."

Prof. Pickering states, in the preface, that when the brightness exceeds 6.5 it is difficult to classify the spectrum with certainty. The photographic magnitudes of these stars are $6.65,6.45,6.44$ respectively.

As regards the fourth type, it is stated (p. 3) that "the letter $\mathrm{N}$ is reserved for spectra of the fourth type, although no star of this type is bright enough to appear in the Draper Catalogue, owing to the red colour of all such 